\title{
BMJ open Disseminating results to clinical trial participants: a qualitative review of patient understanding in a post-trial population
}

\author{
Julie Lorraine Darbyshire, Hermione Clare Price
}

To cite: Darbyshire JL, Price HC. Disseminating results to clinical trial participants: a qualitative review of patient understanding in a post-trial population. BMJ Open 2012;2:e001252. doi:10.1136/bmjopen-2012001252

- Prepublication history and additional material for this paper are available online. To view these files please visit the journal online (http:// dx.doi.org/10.1136/bmjopen2012-001252).

Received 17 April 2012 Accepted 21 August 2012

This final article is available for use under the terms of the Creative Commons Attribution Non-Commercial 2.0 Licence; see http://bmjopen.bmj.com

Diabetes Trials Unit, University of Oxford, Oxford, UK

\section{Correspondence to}

Dr Julie Lorraine Darbyshire; Julie.Darbyshire@ndcn.ox.ac. uk

\section{ABSTRACT}

Objective: To identify the most appropriate format for results dissemination to maximise understanding of trial results.

Design: Qualitative.

Setting: Of the original 58 4-T trial centres, 34 agreed to take part in this ancillary research.

Participants: All participants from these centres were eligible. All 343 participants were sent questionnaires.

Primary and secondary outcome measures: The low response rate meant that we were unable to make any firm conclusions about the patients' preferred method of dissemination; however, we were able to comment on the level of understanding demonstrated by the trial participants.

Results: All 40 (12\%) returned questionnaires were received from 15 centres. We received no questionnaires from over half of the centres. The questionnaires which were returned demonstrated broad satisfaction with the results letter, general enthusiasm for the trial and a variable level of understanding of the results; however, there was a high proportion of responders who were not clear on why the research was undertaken or what the results meant.

Conclusions: The low response rate may be related to delays during the trial set-up process suggesting that interest in a study quickly wanes for both patients and centres. From this we deduce that rapid dissemination of results is needed if it is to have any impact at all. The responders are likely to reflect a biased cohort who were both enthusiastic about the research and who had a good experience during their 3 years in the $4-T$ trial. It is perhaps not surprising therefore that the overview is positive. That this population was still not fully informed about the purpose of the research would seem to confirm a low level of understanding among the general public which we suggest should be addressed during the consent process.

\section{OBJECTIVE}

Clinical trial results are generally published within the healthcare community and rarely disseminated beyond scientific publications. ${ }^{1}$

\section{ARTICLE SUMMARY}

Article focus

- Investigation into participant satisfaction with method of dissemination and understanding of clinical trial results.

- Exploration into reasons for participation in clinical trials.

- Suggestions to improve patient response to post-study questionnaires.

Key messages

- Responders were broadly satisfied with their trial experience but rarely demonstrated good understanding of results beyond their own treatment needs.

- Study interest seems to wane quickly for both patients and centres.

- Results dissemination needs to form part of protocol development and circulated soon after the end of the trial.

Strengths and limitations of this study

- The low response rate was disappointing, especially as it is likely that those who returned their questionnaires had a positive trial experience leading to a potential bias in the results.

- This motivated population still demonstrated limited understanding of the research indicates that more needs to be done at the time of consent and during the trial.

However, it is increasingly a requirement of research approvals that, wherever possible, the public is involved at all stages of research. It is desirable that results are shared with those who take part, but there remains no consensus on the best method of disseminating study findings. Additionally, although patients participate willingly in clinical trials, it is not known if they are aware of the purpose of their trial, or if patients are actually interested in the results. We have presented information collected retrospectively from clinical centres who had held a patient event to share interim 
results from the 3-year Treat to Target in Type 2 Diabetes (4-T) trial (ISRCTN51125379). ${ }^{2}{ }^{3}$ This experience informed the design of the current work.

This 'coffee morning' approach proved popular with patients, and staff did not find this onerous to organise, but while patients demonstrated awareness of the implications for their own future care, it remained unclear if patients fully understood the results of the study as a whole.

The 4-T trial was an open-label, multicentre trial in which 708 type 2 diabetic participants with suboptimal control (glycated haemoglobin 7-10\%) using oral agents were randomised to the addition of a basal, biphasic or prandial insulin regimen. Patients were followed for 3 years and a second insulin formulation was added if glycaemic control remained inadequate. The final results concluded that patients initiated onto the long-acting insulin detemir who later added prandial doses of aspart achieved good glycaemic control with a lower risk of hypoglycaemia and less weight gain than patients initiated onto either the biphasic aspart or aspart insulins. ${ }^{4}$ Trial results were disseminated to all participants at the end of the study, and we decided to assess the level of understanding among those who took part, as well as their level of satisfaction with the trial experience.

\section{DESIGN}

Simultaneously with peer-reviewed publication, the 4-T centres were emailed a press release and letter detailing the headline results and asked to forward a copy of the letter to all trial participants as soon as possible. Subsequently patients were invited to complete a questionnaire in which they were asked to assess the results letter, identify the main findings of the study from a given list and comment on the results in their own words. The questionnaires were returned in prepaid envelopes to the co-ordinating centre where responses were entered into a simple database. Free text was reviewed and categorised by two researchers. The research was approved in the UK by Oxford REC B; ref 09/H0605/100 and by individual sites in Ireland.

\section{RESULTS}

By the end of the 4-T trial $577(81 \%)$ of the 708 originally randomised patients were still alive and had not withdrawn consent. Of these, 234 patients (41\%) were ineligible as their home site did not take part in this results study. A total of 343 (59\%) patients from 34 $(61 \%)$ trial centres were invited to complete the questionnaire. All of the $40(12 \%)$ returned questionnaires were received from $15(44 \%)$ sites. Responses are summarised in tables 1-3. Responder demographics (table 4) did not differ from the main trial.

When asked to describe the results in their own words, five patients referred to the different effects of each insulin (T40001D: 'Different types of Insulin effect (sic) people in different ways'. T42001R: 'This study has shown that although there are various different types of Insulin which are used to manage the patients HbAlc levels. They were seen to give different side effects such as differing weight gains for each type. Which then increases the need to increase insulin dosage to maintain levels and also varying amounts of hypoglycaemic episodes. Thus resulting in better info for GP's to judge which type is better for each individual patient'. T54007Y: 'This study has shown differences in control of hypoglycaemia and weight gain between the different insulins but overall all three improved control and after 3 years all groups had a similar HbA1c value'.). However, just one (T54007Y) also selected the appropriate options from those offered in the questionnaire.

Ten patients' assessments of the trial focused on how the trial had improved their personal diabetes control, one acknowledging a treatment effect of the second insulin formulation (T54002C: 'although I had many hypo's in the earlier 2 years they did lessen towards the end; which also shows the use of the 2 insulins gives greater control'.) and a further 10 said the trial had led to a better understanding of diabetes in general. Nine others responded with seven different explanations including the recognition that insulin treatment lowers blood glucose, that a computerised algorithm was used to control glucose levels (T42023R: 'All the way through the study my glucose levels were fed into the computers and the amount of insulin increase was recorded, when the trial was over I had no knowledge of how to adjust the insulin for myself'.) and that research leads to improved medical care (T40005E: 'That research can and does have benefits for users of insulin and future treatment decisions' and T24008S: 'The 4T study showed

\begin{tabular}{|c|c|c|c|c|c|c|c|c|}
\hline & & $\begin{array}{l}\text { Completely } \\
\text { dissatisfied }\end{array}$ & Dissatisfied & $\begin{array}{l}\text { Neither satisfied } \\
\text { nor dissatisfied }\end{array}$ & Satisfied & $\begin{array}{l}\text { Completely } \\
\text { Satisfied }\end{array}$ & $\begin{array}{l}\text { No } \\
\text { answer }\end{array}$ & Total \\
\hline 1 & $\begin{array}{l}\text { The time taken to } \\
\text { learn the results of } \\
\text { the study }\end{array}$ & 1 & 0 & 4 & 20 & 15 & 0 & 40 \\
\hline 2 & $\begin{array}{l}\text { The source of } \\
\text { information given } \\
\text { today }\end{array}$ & 1 & 0 & 0 & 26 & 13 & 0 & 40 \\
\hline 3 & $\begin{array}{l}\text { Satisfaction with the } \\
\text { source of information }\end{array}$ & 1 & 0 & 1 & 23 & 14 & 1 & 40 \\
\hline
\end{tabular}


Table 2 General information about the 4-T trial and medical research

\begin{tabular}{|c|c|c|c|c|c|c|c|c|}
\hline & & $\begin{array}{l}\text { Strongly } \\
\text { disagree }\end{array}$ & Disagree & $\begin{array}{l}\text { Neither agree } \\
\text { nor disagree }\end{array}$ & Agree & $\begin{array}{l}\text { Agree } \\
\text { strongly }\end{array}$ & $\begin{array}{l}\text { No } \\
\text { answer }\end{array}$ & Total \\
\hline 4 & $\begin{array}{l}\text { I understood the results presented to } \\
\text { me today }\end{array}$ & 0 & 1 & 4 & 25 & 10 & 0 & 40 \\
\hline 5 & $\begin{array}{l}\text { I understand the risks and benefits of } \\
\text { each insulin }\end{array}$ & 0 & 0 & 3 & 28 & 9 & 0 & 40 \\
\hline 6 & $\begin{array}{l}\text { I understand what I need to do to } \\
\text { continue with my diabetes medication }\end{array}$ & 0 & 0 & 1 & 22 & 16 & 1 & 40 \\
\hline 7 & $\begin{array}{l}\text { The information content of the patient } \\
\text { results letter was about right }\end{array}$ & 0 & 1 & 3 & 31 & 5 & 0 & 40 \\
\hline 8 & $\begin{array}{l}\text { The patient results letter was useful/ } \\
\text { informative? }\end{array}$ & 0 & 1 & 2 & 32 & 5 & 0 & 40 \\
\hline 9 & $\begin{array}{l}\text { Taking part in the } 4-T \text { trial was as I } \\
\text { expected }\end{array}$ & 1 & 0 & 2 & 24 & 13 & 0 & 40 \\
\hline 10 & $\begin{array}{l}\text { I would participate in a similar study } \\
\text { again }\end{array}$ & 1 & 0 & 3 & 11 & 23 & 2 & 40 \\
\hline 11 & $\begin{array}{l}\text { I would be more likely to take part in } \\
\text { a clinical trial if I knew I would receive } \\
\text { the results of the trial at the end }\end{array}$ & 1 & 2 & 5 & 17 & 14 & 1 & 40 \\
\hline 12 & $\begin{array}{l}\text { Receiving the study results improved } \\
\text { the overall experience of taking part }\end{array}$ & 1 & 1 & 3 & 18 & 16 & 1 & 40 \\
\hline 13 & $\begin{array}{l}\text { I would have preferred to attend a } \\
\text { coffee morning to learn the trial } \\
\text { results }\end{array}$ & 3 & 7 & 10 & 7 & 12 & 1 & 40 \\
\hline 14 & $\begin{array}{l}\text { I would have preferred to take part in } \\
\text { a telephone conference to learn the } \\
\text { trial results }\end{array}$ & 6 & 12 & 15 & 3 & 2 & 2 & 40 \\
\hline
\end{tabular}

me and I hope others that with the help that I got will open their eyes as to what work has being done by people that care in study so much'). Five patients did not complete this section of the questionnaire.

\section{CONCLUSION}

The disappointingly low response rate was a surprise; however, we can suggest reasons for the apparent lack of interest. This additional research was developed towards the end of the main study and neither patients nor sites were expecting further involvement beyond their final 4-T visit. We also experienced long delays in local approval processes. We have no robust statistics, but many local research and development $(\mathrm{R} \& \mathrm{D})$ offices took a very long time to review the documents, some requiring us to re-submit more than once. We believe these delays directly impacted on the response rate since rather than being able to send the recruitment packs to 4-T patients soon after the trial results were published in October 2009, they were eventually circulated 6-8 months later. For all patients this would have been almost 12 months after they had completed the trial; for many it would have been up to 2.5 years after their final $4-\mathrm{T}$ visit. It is possible patients felt disconnected from the trial, or that the results had little relevance to them at this late stage.

Interestingly, $23(41 \%)$ of the original 4-T centres declined to take part in this follow-on study. By the time they were asked to distribute recruitment packs, many centres had archived their 4-T files and any loyalty they may have had towards 4-T is likely to have been supplanted by newer research studies. Additionally, we received no patient questionnaires from 19 (56\%) of the 34 sites who did agree to take part, and it is possible the recruitment packs were not circulated. We have no detailed statistics on reasons for site refusal but anecdotally we can report that some were reluctant to distribute recruitment packs on behalf of the research team as there was no financial recompense. The study was also ineligible for the NIHR Research Network portfolio for the same reason. While we appreciate that $\mathrm{R} \& \mathrm{D}$ offices have a responsibility to ensure their staff are adequately resourced, we feel that this low budget ancillary study is something that the network could have supported. With hindsight it may have been beneficial to convert the 4-T research sites to Patient Identification Centres and request permission from the National Information Governance Board for Health and Social Care to recruit via the central co-ordinating office. Had we been able to contact patients directly we may have had better representation as we would have been able to include all 577 patients in the initial recruitment phase. We would also have been able to follow-up non-responders which we were unable to do through the sites, although this is a recommended practice. ${ }^{5}$

Although we initially intended to investigate patient understanding of trial results and the preferred method of receiving end-of-trial information, the low response 
Table 3 Reasons for taking part in the 4-T trial and patient experience during the trial

\begin{tabular}{|c|c|}
\hline \multicolumn{2}{|l|}{$\begin{array}{l}\text { Why did you take part in the } 4-T \text { trial? (patients were } \\
\text { invited to add free text and could specify more than } \\
\text { one reason) }\end{array}$} \\
\hline Clinical care team recommendation & 17 \\
\hline Improving own control & 15 \\
\hline Helping patients in the future & 11 \\
\hline Care in trial better than standard & 10 \\
\hline Improve personal control of diabetes & 8 \\
\hline Wanted to find out more about diabetes & 4 \\
\hline Needed insulin for treatment of diabetes & 4 \\
\hline 4-T was a 'no risk' trial & 2 \\
\hline Wanted to share experiences of diabetes with others & 2 \\
\hline \multicolumn{2}{|l|}{$\begin{array}{l}\text { Did you find anything unpleasant while in the trial? } \\
\text { (patients were invited to add free text and were not } \\
\text { limited to one negative response) }\end{array}$} \\
\hline Nothing/no answer & 28 \\
\hline Small inconveniences & 7 \\
\hline SMCG readings & 3 \\
\hline Attending clinic visits & 3 \\
\hline Weight gain & 3 \\
\hline Blood tests & 1 \\
\hline \multicolumn{2}{|l|}{ Evidence of understanding } \\
\hline $\begin{array}{l}\text { Different types of insulin are associated with different } \\
\text { hypoglycaemia rates }\end{array}$ & 17 \\
\hline Hypoglycaemia is a risk with insulin treatment & 11 \\
\hline Insulin treatment was not associated with weight gain & 10 \\
\hline Insulin treatment lowered blood glucose & 6 \\
\hline $\begin{array}{l}\text { Identified all correct responses and no incorrect } \\
\text { responses }\end{array}$ & 5 \\
\hline
\end{tabular}

rate makes it difficult to extrapolate findings to the wider population. It is clear that the most of the patients who completed the questionnaire felt well informed about the trial and for the most part had a positive trial experience. This is likely to have influenced their

Table 4 Demographics of those who returned their questionnaire compared against the main 4-T study

\begin{tabular}{llll}
\hline & $\begin{array}{l}\text { Dissemination } \\
\text { study }\end{array}$ & Main study & $\begin{array}{c}\text { p Value } \\
\text { (t test) }\end{array}$ \\
\hline $\begin{array}{l}\text { Gender } \\
\text { Number of } \\
\text { females, N (\%) }\end{array}$ & $14(35.0)$ & $254(35.9)$ & 0.91 \\
$\begin{array}{l}\text { Number of } \\
\text { males, N (\%) }\end{array}$ & $26(65.0)$ & $454(64.1)$ & \\
$\begin{array}{l}\text { Total } \\
\text { Race } \\
\text { Number of }\end{array}$ & 40 & 708 & \\
$\begin{array}{l}\text { White, N (\%) } \\
\text { Number of } \\
\text { non-White, N } \\
\begin{array}{l}\text { (\%) } \\
\text { Total }\end{array}\end{array}$ & $37(92.5)$ & $635(92.2)$ & 0.57 \\
$\begin{array}{l}\text { Age } \\
\text { Mean (SD) }\end{array}$ & $64.1( \pm 8.2)$ & $73(7.8)$ & \\
\hline
\end{tabular}

decision to return the documents therefore care should be taken when interpreting these results.

As we found previously, ${ }^{3}$ patients clearly demonstrate appreciation for local clinical staff. Our results in table 1 suggest that although there is a cohort of patients who are not interested in the trial beyond their own treatment, the majority of patients thought receiving the results improved their trial experience. This supports the need to share the full results and not just information which will affect an individual's future care as has often been the case previously. ${ }^{6}$ Another study disseminated results via teleconference ${ }^{7}$ and this was warmly received by the press. ${ }^{8}$ We were keen to see if this would be widely received as an acceptable method for 4-T patients. It is interesting to note the lack of interest expressed compared with the coffee morning option. This may be because some patients had a previous positive experience of a 4-T coffee morning. It also may relate to the age of $4-\mathrm{T}$ patients, who were on average over 10 years older than the Huntington disease patients. The Huntington patients may also have had greater levels of disability, which might constrain their choice of medium for results dissemination.

Although most patients chose at least one correct option for the trial results, when asked to describe the findings in their own words we found patients tended to focus on their individual care with over a quarter describing personal improvements in diabetes control. This correlates with the reasons why patients entered the trial (table 3), is consistent with other research, ${ }^{9} 10$ and indicates that the purpose of clinical research is not well understood by the public. We suggest this should be better communicated at the outset, and then reinforced throughout the trial process.

Communication of scientific research to lay audiences is a priority for both academic and political communities. Scientific scepticism is common in developed nations, yet only $25 \%$ of European and American public are considered 'scientifically literate'. ${ }^{11}$ Researchers have a responsibility to report their work and the Canadian Health Services Research Foundation recommends that when considering dissemination, information is 'clear, simple ... tailored for each audience based on knowledge user need' ${ }^{12}$ It is a requirement that trials registered with ClinicalTrials. gov publish in the public domain, and 4-T results are available via this website. We postulate however that the ClinicalTrials.gov template does not encourage lay review.

The 4-T model of providing results to participants via a social event was well received by patients and sites and shows promise as a method of sharing information. We believe this study illustrates that results dissemination plans should occur alongside protocol development forming part of the overall study and included in reimbursement calculations. We have perhaps also shown that interest in studies quickly wanes for both patients and centre staff so any dissemination is likely to be needed rapidly if it is to have any impact at all. It remains to be seen if the interactive opportunities 
offered by local coffee mornings would lead to greater understanding of research in general.

Acknowledgements The authors would like to thank the patients and staff of the 4-T study for their time and interest in the research. They would also like to thank Ada Tse of the Diabetes Trials Unit for administrative support before, during and after the study.

Contributors JLD and HCP devised the study and wrote the protocol. JLD wrote the initial draft of the manuscript. Both authors take responsibility for the final content.

Funding The main 4-T study was funded and sponsored by Novo Nordisk Ltd.

Competing interests JLD has no competing interests. HCP has received payment from Novo Nordisk for sitting on advisory panels and also from Novo Nordisk, Eli Lilly, Sanofi and Boehringer Ingelheim for lectures and travel expenses.

Provenance and peer review Not commissioned; externally peer reviewed.

Data sharing statement Original data are available on request from the Diabetes Trials Unit, University of Oxford. Please contact the corresponding author in the first instance.

\section{REFERENCES}

1. Chen PG, Diaz N, Lucas G, et al. Dissemination of results in community-based participatory research. Am J Prev Med 2010;39:372-8
2. Holman R, Thorne K, Farmer A, et al. Addition of biphasic, prandial, or basal insulin to oral therapy in type 2 diabetes. N Engl $J$ Med 2007;357:1716-30.

3. Darbyshire JL, Holman RR, Price HC. Presenting the results of clinical trials to participants. Clin Med 2009;9:415-16.

4. Holman RR, Farmer AJ, Davies MJ, et al. For the 4-T study group, three-year efficacy of complex insulin regimens in type 2 diabetes. N Engl J Med 2009;361:1736-47.

5. McColl E, Jacoby A, Thomas L, et al. Design and use of questionnaires: a review of best practice applicable to surveys of health service staff and patients. Health Technol Assess 2001;5.

6. Partridge A, Hackett N, Blood E, et al. Oncology physician and nurse practices and attitudes regarding offering clinical trial results to study participants. J Natl Cancer Inst 2004;96:629-32.

7. Dorsey ER, Beck CA, Adams M, et al. Communicating clinical trial results to research participants. Arch Neurol 2008;65:1590-5.

8. Flore K. Clinical trial participants often left in the dark on results. 2008. http://www.medpagetoday.com/PublicHealthPolicy/ ClinicalTrials/12088 (accessed Feb 2012).

9. Locock L, Smith L. Personal experiences of taking part in clinical trials-a qualitative study. J Patient Educ Couns 2011;84:303-09 doi:10.1016/i.pec.2011.06.002

10. Lawton J, Fox A, Fox C, et al. Participating in the UKPDS: a qualitative study of patients' experiences. $\mathrm{Br} J$ Gen Pract 2003;53:394-8.

11. Hargreaves I, Ferguson G. Who's misunderstanding whom? Economic and Social Research Council report, 12 September 2000 http://www.esrc.ac.uk/_images/Whos misunderstanding_whom tcm8-13560.pdf (accessed Feb 2012)

12. Gagnon ML. Moving knowledge to action through dissemination and exchange. J Clin Epidemiol 2011;64:25-31. doi 10.1016/j.jclinepi. 2009.08.013 